DOI No: http://dx.doi.org/10.29228/Joh.52471

Authenticity process is conducted by

Makale Türü: Araştırma makalesi

intihal.net

Geliş Tarihi: 26-08-2021

Kabul Tarihi: 25-10-2021

On-line Yayın: 31-10-2021

Article Type: Research article Submitted: 26-08-2021

Accepted: 25-10-2021

Published Online: 31-10-2021

Atıf Bilgisi / Reference Information

Cengiz, D. (2021). Tahtacıların Mengi Oyunu. Journal of History School, 54, 36583679 .

\title{
TAHTACILARIN MENGİ OYUNU
}

\section{Daimi CENGIZ ${ }^{1}$}

\section{$\ddot{\mathbf{O z}}$}

Tahtacılar Horasan'dan gelip Anadolu'ya yerleşen Alevi Türkmen topluluğudur. Şamanist ve batıni Heterodoks itikat öğelerini inançlarında bir arada yaşarlar. Yavuz Sultan Selim'in Çaldıran Muharebesi (1514) akabinde Alevi/Kızılbaş tayfalarına karşı yürüttüğü kıyım sonucu bir kesim Türkmen Alevisi de Akdeniz ve Ege bölgesinin dağlık kuytuluk alanlarına sığındılar. Bu alanlarda ağaç işini ve tahtacılığı kendilerine meslek edindiler. $\mathrm{Bu}$ nedenle dışarıdan mesleken kendilerine Tahtacı dendi. Ama onlar kendilerini Türkmen Alevisi olarak tanımladılar. Tahtacılar ağacın ruhunun olduğuna inanırlar. Ağacı kutsal değer olarak görürler. Onlara göre ağaç ruhun barınağıdır. Tahtacı ağaç ile özdeştir. Yaşı ağaç ise ulu ve yaşlı kişilerle özdeştir. Tahtacılar Ağaçeri soyundandırlar. Ağaçeri torunlarıdır. Ağacın kutsanmasının Anadolu'da binlerce yıllık tarihi vardır. Anadolu mitolojisinde bunu bariz şekilde görmek mümkündür. Tahtacılar ve onların Mengi oyununa dair literatür ve alan araştırma verileri sınırlıdır. Amacımız dağınık olan literatürü derleyerek, yaptı̆̆ımız alan araştırması verileri ile birleştirerek Mengi oyunu hakkında bilinen dağarcığın sınırlarını zorlamaktır. Tahtacıların doğum, düğün, sünnet, nişan vb. eğlence ortamında icra edilen, genç erkek ve kızları samah kültürü ve oyunu hakkında bilgilendirmek ve eğitmek amacı ile Dışarı Samahı ya da Tarikat Samahı adı altında oynanan Mengi oyunu vardır. Mengiler iki türlüdür: 1. Eski Mengiler 2. Yeni Mengiler. Alanda İtikadi Mengiler ve İtikat dışı Mengiler repertuarını özellikle bulguladık. İtikadi Mengilerin Samah ile tema, figür ve hareket tarzı itibarı ile benzerliği ve ayrılığını da alan çalışması ile belirleyerek kayıt altına aldık. Tahtacıların Meslek/iş ritmi (tahta biçme ritmi) ile mengi’nin melodik ritmi ve düzüm kalplarının (2

${ }^{1}$ Dr. Öğr. Üyesi., Munzur Üniversitesi Güzel Sanatlar, Tasarım ve Mimarlık Fakültesi, Müzik Bölümü, d.cengiz@gmx.net, Orcid: 0000-0002-8034-9127 


\title{
Tahtacilarin Mengi Oyunu
}

22 3) aynı olduğunu saptadık. Tahtacıların ifadesi ile” Mengi Tahtacının mührüdür”. Tahtacı Alevi Türkmenler arasında oynanan geleneksel oyun olup samaha yakın özellikler gösteren karşılama türü çoşkulu bir oyundur. Diğer bir ifade ile Mengi samahtan kopan ve samahi özellikler gösteren, samah ile karşılama arası bir oyundur.

Anahtar Sözcükler: Mengi, Tahtac1, Alevi, Türkmen, Halk oyunu

\section{Mengi Game of Tahtacis}

\begin{abstract}
Tahtac1 ("Woodworkers") is an Alawite Turkoman community, arrived from Khorasan and settled in the Asia Minor. They experience and practice the faith aspects of Shamanism and esoteric Heterodox together in their rituals and beliefs. Following the Battle of Chaldiran the massacre led by Selim I., known as Selim the Grim or Selim the Resolute, against the Alawites/Qizilbash communities has resulted in certain Turkoman Alawites taken shelter at the mountainous secluded areas of the Mediterranean and Aegean Regions. They have adopted the profession of woodworkers and that's why they are named as Tahtac1 ("Woodworkers"). However, they continue to define themselves as Turkoman Alawites. The woodcutters believe that the tree has its soul. They see the tree as a sacred value. According to them, the Tree is the shelter of the soul. The woodcutters are identical to the tree. The great tree is identical with the old and great people. The woodcutters are descended from the woodcutters. They are the descendants of Ağaçeri. There is a history of thousands of years in Anatolia about the consecration of the tree. It is possible to see this clearly in Anatolian mythology. The literature and the data from the field studies on the Tahtaci and the Mengi ("whirling") folkdance are quite limited. Our objective is to compile the literature with the scattered state, combining with the data of our field study and push beyond the boundaries of the known vocabulary regarding the Mengi folkdance. Tahtaci community practice the folkdance of Mengi, usually named as Dışarı Samahı (Outer Whirling) or Tarikat Samahı (Sect Whirling) in the special occasions such as birth, wedding, circumcision, engagement, etc., for the purpose of informing and educating the young boys and girls on the semah (whirling) culture and folkdance. Mengi folkdance has two types: 1. Ancient Mengi and 2. New Mengi. We have particularly discovered the repertories of Faith Mengi and Non-Faith Mengi on the field. We have identified and recorded the similarity and differences between the Faith Mengi and Semah in terms of theme, figures and movement style with the field study. We have identified that the occupation/profession rhythm of the Tahtac1 (wood-chopping rhythm) and Mengi's melodic rhythm and sequence patterns $\left(\begin{array}{llll}2 & 2 & 2 & 3\end{array}\right)$ are exactly the same. As Tahtac expresses, "Mengi is the seal of the Tahtac1". It is a traditional and enthusiastic folkdance with karsilamas (welcoming, greeting) style practiced by the Tahtac1 Turkoman Alawites with features similar to semah. In other words, Mengi is a folkdance originally formed out of semah bearing the features between the semah and karsilamas.
\end{abstract}




\section{Daimi CENGİZ}

Keywords: Mengi, Tahtac1, Alevi, Turkoman, Folkdance

\section{GİRIŞ}

Araştırmamız Tahtacı Türkmen Alevilerinin Mengi oyununa dairdir. Mengi oyununu anlamlandırmak için Tahtacı Türkmenlerinin kısaca kökeni, tarihi, itikatı, yaşam şekli ve alanı hakkında bilgi edinmek gerekir.

Yazılı kaynaklardan ve alan araştırmaları verilerinden bu oyunu oynayan Tahtacıları tanımak mümkündür. Tahtacı Türkmenleri arasında 1950 yılında alan araştırması yapan Naci Kum onların yaşam tarzına dair şu tespitte bulunur: Sırf tahtacılık zanaatı ile geçinen Tahtacılar Karaçadır ve Derimevi (Toprak ev) denilen barınaklarda yaşarlar. Ağaç taşımak için katır beslerler. Dışa kapalı inanç ve geleneklerine kaskatı bağlı olan bu batıni topluluk dışarıdan evliliğe kapalıdır (Kum, 1950, s. 175).

Tarihen daha gerilere gitmek gerekir. Faruk Sümer Tahtacıları Maraş dağlarında 12. yy'da Ağaçeri olarak tanınan bu aşiretlerin, Osmanlının vergi toplamak amacı ile 16. yy'dan sonra düzenlediği tapu tahrir defterlerinde Cemaat-1 Tahtacıyan olarak kaydedildiğini belirtir (Sümer, 1980, s. 528).

Sümer aynı eserin 1972 baskısında Tahtacıları şöyle tarifler: Tahtacı sözcügünün 1rki bir anlamı yoktur. Bu isim hayvancılık ve ziraat yerine ormanda tahta biçmek ve dilmek yapma icraatı ile uğraşan Türk oymağına verilir. Bu oymak A ğaçeri Türkmenlerin evlatları olup Alevi itikatını taşırlar. Çok çalışkan zümredir (Sümer, 1972, s. 174).

Tahtacılar üzerine alan çalışması yapan Ali Aksüt'e göre ise Tahtacılar İran coğrafyasını aşarak Anadolu’ya göçmüş, Alevi itikatına mensup farklı Türkmen zümrelerinden meydana gelmiş, Yanyatır ve Hacı Emirli Alevi ocaklarına mensup ve sonradan ağaç ameleliğini meslek edinmiş, dişarıdan kendilerine Türkmen ismi iliştirilmiş Türkmen Alevi zümreleridir (Aksüt, 2003, s.10).

Tahtacı aşiretlerinin yürüyüşü Doğu Toroslardan, Antep, Maraş ve Tarsus'tan başladı. Mersin, Silifke, Antalya, Aydın ve İzmir üzerinden Ege'ye hatta Trakya'ya kadar vard1. Tahtaciların Toros kolunun bir kesimi Osmanlılarca fethedildikten sonra Kıbrıs'a göçertildi. Araştırmacı Kehl'e göre bir kısım Tahtacı da Sultan Murat döneminde Midilli adasına sürüldü (Kehl, 1987, s. 13).

Murat Küçük göre ise Tahtacılar Toroslardan Akdeniz kıyı şeridinde Ege'ye doğru yol alırken iki ulu ocak pirlerini geride (başlangıç yerinde-DC) bıraktılar. Hacı Emir ocağının piri addedilen İbrahim-i Sani AdanaGüvercinlik'te, Yanyatır ocağı piri Dur Hasan Dede ise Ceyhan-Dur Hasan 
mevkiinde kaldı. Anadolu'nun çeşitli yerlerinde meskûn olan Tahtacı oymakları mutlaka adı zikredilen bu iki ocaktan birine mensupturlar.

M. Küçük devamla Ziya Yörükan'ın Tahtacı boyunu/aşiretlerini 1920'lerde 15 alt boy olarak tasnif edişini şöyle aktarır: 1. Çobanl1, 2. Çaylak, 3. Sivri Kulak, 4. Cingöz, 5. Üsküdarl1, 6. Enseli, 7. Ali Abal1, 8. Cilcili, 9. Mazıcı, 10. Kahyalı, 11. Göğçeli, 12. Naçarlı, 13. Sehepli, 14. Kabaklı, 15. Aydınlı. Bu aşiretlerden 12'si Yanyatır ocağına ve 3'ü ise Hacı Emirli ocağına bağlıdır (Küçük, 2009, s. 29-30). Hacı Emirliler mengileri Silifke'den Ege'ye taşıdılar. Aydın ili Karacasu ilçesi boyasın köylüleri Kabaklar ya da Kabaklılar olarak bilinir. Danişmentlilere bağlı konar-göçer Türkmen Yörükanı'dır. Musul'dan Anadolu'ya geldiklerini kaynaklar belirtir (Türkay, 1979, s. 446). Kabak Abdal Uşağı da denilen bu topluluk Gaziantep-Islahiye ilçesi Kabaklar köyünden Anadolu'ya dağılmıştır. Yani Islahiye, Adana, Serik, Antalya ve Elmalı üzerinden Ege'ye göç etmişlerdir (Orhonlu, 1957, s. 69). Boyasınlar Islahiye Kabaklar köyünde doğup Çerçili köyünde türbesi bulunan hacı Emirli İbrahim-i Sani evlatlarından olup, Aydın-Kızılpınar'ı ocak merkezi eden Şehepli'ye tabi Hacı Emir Dede ocağına bağlıdırlar (Aksüt, 2003, s. 69).

Silifke tahtacıları üzerine araştırma yapan Ö. Seyhan da onların geçmişi, inancı ve yaşam tarzları hakkında şu açıklamayı yapar: Silifke Tahtacıları Horasan'dan geldiklerini iddia ederler. Alevi ve Türkmen olan bu aşiretler önceleri hayvancılıkla geçinirlermiş. Çevrenin sunni halkı tarafından inançları gereği hakir görülürlermiş. Yavuz Sultan Selim'in Alevi siyaseti (1514) sonrası ormanlara, dağlara sığınmışlar. Zorunlu olarak ağaç işlerini kendilerine meslek edinmişler. Ağaç ve tahta işinden ötürü kendilerine Tahtacı denmiş. Türk gelenek ve göreneklerini en iyi saklayıp günümüze ulaştıran Alevi Türkmenlerdir. Şamanizmin kalıntıları geleneklerinde saklıdır. Kendi iç sorunlarını mahkemeye gitmeden-görgü cemi ile-hallederler. Kız kaçırma adetleri yoktur. Çok misafirperverdirler. En eski gelenekleri arasında ölüyü mezara götürürlerken saz, kemane çalmak vardır. Hep birlikte ağlaşı-çığrışı ağıtlar söylerler. Ölüsünü toprağa verene kadar bu ölüm nefeslerinin icrası devam ederler (Seyhan, 1967, s. 4581).

$\mathrm{Bu}$ tarihi belirlemeden hareketle Tahtacıların kimliği hakkında şu özetlemeyi yapabiliriz: Onlar Horasan'dan Anadolu'ya geçen batıni itikat mensubu aşiretler topluluğudur. Tarihte Cemaat-1 Tahtaciyan olarak bilinirler.

Doğu Toroslardan Akdeniz kıyıları boyunca ilerleyip Ege'ye yayılan Alevi Türkmen boyudur. Kıyımlar sonucu dağların kuytuluklarına sığınan bu Ağaçeri topluluğu, Şamanist ve batını tasavvufi heterodoks inanç öğelerini bir arada yaşarlar. Ağaç işini meslek edindiklerinden dışarıdan kendilerine Tahtacı 


\section{Daimi CENGİZ}

denmiştir. Ama onlar her zaman kendilerini Horasan'dan gelen Alevi Türkmen olarak tanımlarlar.

Tahtacılar Anadolu'da Kaz dağına, Kırtıl dağına, Alın Pınarı, Sarıkız tepesi vb. gibi dağ doruklarına adak götürürler. Adakları kutsal sayılan dağın tepesinde keserler. Ağaçların onların yaşamında müstesna yeri vardır. Ağaç işleri ile iştigal eden bu topluluğun ağaca dair kutsiyetine değinmek gerekir: Tahtacilar ağacın ruhunun olduğuna inanırlar. Ağacı kutsal değer olarak görürler. Onlara göre ağaç ruhun barınağıdır. Tahtacı ağaç ile özdeştir. Yaşlı ağaç ise ulu ve yaşlı kişilerle özdeştir. Tahtacılar Ağaçeri soyundandırlar. Ağaçeri torunlarıdır. Ağacın kutsanmasının Anadolu'da binlerce yıllık tarihi vardır. Anadolu mitolojisinde bunu bariz şekilde görmek mümkündür. Tahtacılar inançları gereği yaşlı ağaçları ve taze filizleri kesmezler. Kesmek zorunda olduklarında ise mutlaka "başı tünekli ağaç koymadık" diyerek üzüntülerini ifade ederler. Onlara göre yaşlı ağaç ak sakallı yaşlı pirdir. Muharrem orucunda balta kullanmazlar. Ağaç kesimi zamanında: Bismilllahirahmanirrahim! Ya Allah, ya Muhammed ya Ali! Ya Habib Neccar sen kolaylık ver! diyerek siftah ederler. Yaş ağaç kestiği için işi ters giden Tahtacı kahırlanır: "Tahtacıların piri bile kırk katırla dağda aç kalmış bizim mi karnımız doyacak” derler. Burada ağaç kestikleri için kendilerini suçlarlar. Tahtacılar en temiz ve en yeni giysileri ile ağaç kesimi yerine giderler. Kesime gitmeden önce obaya yetecek kadar kurbanlık koyunu ayırırlar. İçel Kuzucubelen, Silifke, Kırtıl, Mut köyleri, Muğla ili Ula ilçesi Çörüş köyünde meşe koruları kutsal ziyaret yeri olarak kabul görür. Kurbanlar, adaklar bu meşeliklere adanır. Bu bölgelerde Orman Dede, Çalı Dede, Gözcü Dede, Hayıt Dede, Gül Dede gibi kutsal sayılan mekanlar ağaç adını taşırlar.

Ağaç; kundaktan sonra kullandıkları beşiğe, üstünde atlayıp çevreye baktıkları eşiğe, ağızlarına getirdikleri kaşığa ve mezar başına diktikleri ağaç ya da fideye kadar Tahtacının yaşamında yer alır. Ağaca dair kutsiyet kültürü dışında Tarihte Cemaat-1 Tahtaciyan, günümüzde ise Tahtac1/Tahtacı Türkmen Alevileri olarak bilinen bu topluluğun kendine özgü dini, yarı dini ve din dışı oyun kültürü de vardır. Sadece Tahtacılar ile bir kesim Abdal Alevilerinin oynadığı mengi oyunu dinivari, yarı dini oyun sinıflamasına girer. Tahtacı ve Abdal Alevileri Ayın-1 Cem törenlerinde samah dönerler. Samah dini ritüelin vazgeçilmezi, ilahi aşk ile oynanan oyun olup 12 Hizmet dahilindedir. Ege ve Akdeniz Tahtacıları arasında Tarikat Samahı ya da Dışarı samahı denilen Mengi oynanır. Tahtacılarda kız ve erkek gençler samah oynamayı öğrenmek amaçlı samahvari bu oyunu oynarlar. Mengi Tahtacilarda bir semboldür. Ayin-i Cem dişında dügüun, nişan, sünnet ve diğer eğlence ortamlarında karşılıklı ve topluca oynadıkları menginin cemaat içinde ve literatüre geçmiş tanımı vardır. 
En eski yazılı Türk kaynaklarından olan Divanü Lügat-it Türk'te mengi şöyle tanımlanır: Menğgü: Ebedi, daimi, sonsuz, ebedilik, sonsuzluk (Atalay, 1991, s. 441).

Mengi koşmak ve yürümek anlamına da gelir. Uygurca'da mengi hatta mingi sıfat olmuştur. Yüksek, ali, semavi demektir. Manmak ya da minmet fiilinden gelme olarak binmek, çıkmak, atlanmak anlamındadır (Gazimihal, 1951, s. 338). E. Kormaz'a göre ise mengi Mersin ve cıvarında kadınlı-erkekli oynanan ve Tahtacıların geleneksel oyunları arasında yer alan, samaha yakın özellikler gösteren karş1lama türü bir oyundur (Korkmaz, 1994, s. 236).

\section{Mengi Oyunu}

N. Çıblak'a göre mengi kadın ve erkekler tarafindan oynanan karşılama türü bir oyundur. Davul eşliğinde oynanır. Ağırlama kısmı sonrası yeldirme kısmı gelir. Tahtacı ve Abdal Alevileri tarafından coşku ile oynanır. Dügün, sünnet, nişan vb. ortamlarda yüzyüze en az iki kişi ile veya topluca el çırpılarak oynanır.

Mengi oyunu sevgi ve dostluğu simgeler. Kabak kemane, zilli def, davul eşliğinde oynanır. Ayaklarda sekme, diz kırma, öne eğilme ve kol sallama menginin başlıca figürleridir (Çıblak; 2005: 326).

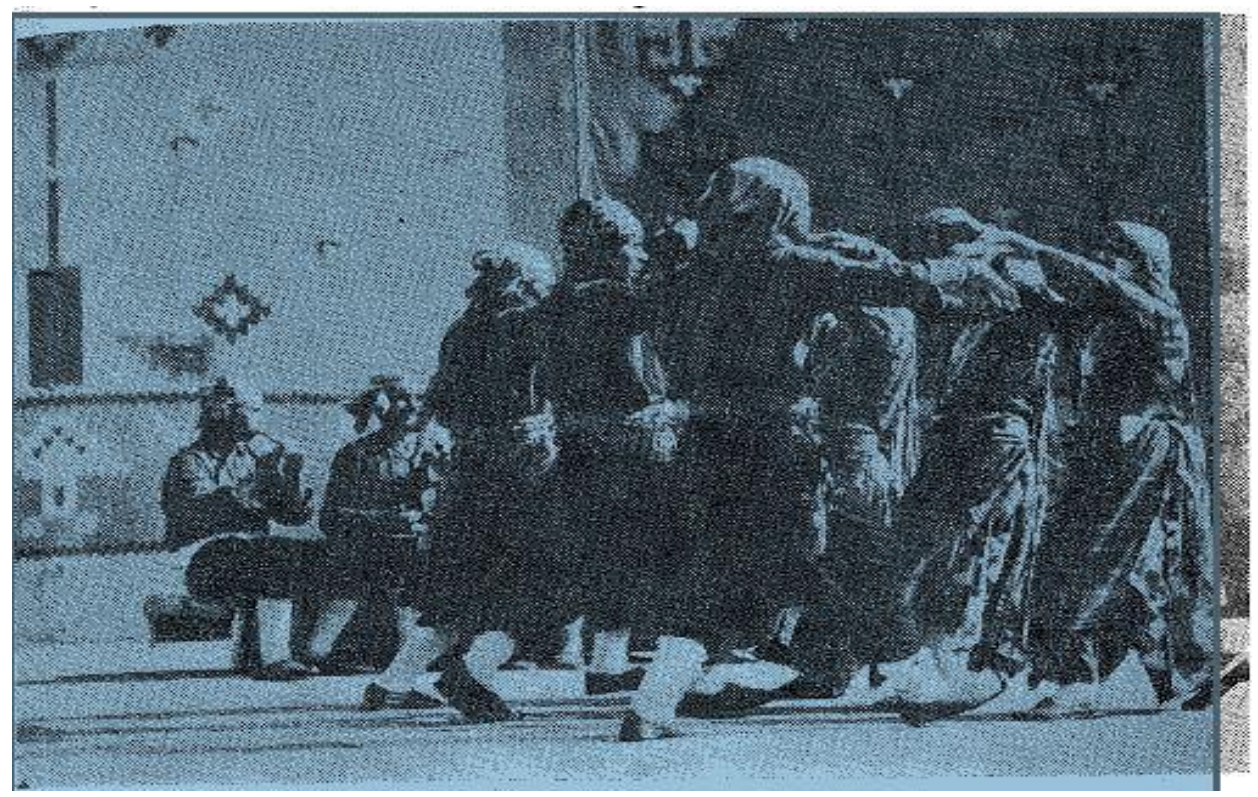




\section{Daimi CENGİZ}

Kaynak kişi İsmail Çakar'a göre Tahtacı Alevileri çevrelerinde yer yer Alevi nefeslerinden oluşan mengilere Tarikat Samahı, Dışarı Samahı da derler. Tarikat Samahı 12 Hizmet dışında genç kuşaklara samah kültürünü benimsetmek ve öğretmek amacı ile samah disiplininden ayrılmadan icra edilir.

Tarsus yöresi Kaburga Gediği, Çamalan ve İçel-Silifke ilçesi Kırtıl köyünde de mengi oynanır. Kaynak kişi Ayşe Kılıç'a göre samaha benziyen bu oyun obanın yaşlısına/büyüğüne sırt dönülmeden oynanan eğlence oyunudur. Sadece kadınlar ya da erkek ve kadınlarca oynanır. Bu oyunda yaşlıya sırt dönülmeden oynama bize samahlarda semazenlerin dedeye, çerağa sirt dönmeden oynamalarını hatırlatmaktadır. Bu davranış samahın mengi üzerindeki etkisine delalettir. Mengi Tahtacıların icra ettikleri samahlarla figürsel ve ifade benzerliği olan bir oyundur. Kaynak kişi Esma Biçer Mengi oyunu ve samaha dair şu belirlemede bulunur: Tahtacılarda toplu mengi oyunu oynama geleneği de vardır. Mengi her zaman oynanabilir. Ama samah sadece Ayin-i Cem ritüeli dahilinde dönülür. Mengi mutlaka coşku içinde oynanır. Oynandığında 90'lık nene bile yerinden kalkıp bu coşkuya katılır.

Aydın-Boyasın'da mengi oyununu icra edenler doğudan gelip yerleşen Tahtacı Alevileridir. Mengi az da olsa zikri özellikler taşır. Mengi ne tek başına bir oyun ne de tamamen ibadet içinde yapılan bir zikirdir. Zikrimsi bir coşkunun müzik eşliğinde dişa vurumu olan mistik bir oyundur. Bu mistik özellik özellikle Alevi-Bektaşi şairlere ait nefeslerin icra edildiği mengilerde açıkça görülür. Cengiz'e göre mengi Tahtacılar arasında geleneksel bir oyun olup ve samaha yakın özellikler gösteren karşılama türü halk oyunudur. Mengi samahtan kopan ama samahi özellikler taşıyan, samah ile karşılama arası bir oyundur (Cengiz, 2020, s. 51).

Alan Araştırmacısı Nacı Kum'a göre mengi oyunu zahir hayata dairdir. Düğün, nişan, sünnet vb. eğlencelerde gençler tarafından icra edilir. Büyükler meclisinde oynanmaz, ayıptır. Mengi samahtan ayrı olarak türkülü oyun havası formunda olup çok hareketlidir. Genç kız ve erkekler tarafından kaşıklar şaklatılarak oynanır (Kum, 1950, s. 175).

Mengi Teke yöresinde birlikte/grupça, yürük ve karşılıklı oynanan Zeybek danslarının lokal ismidir. Dairevi şekilde bir sıralanışla icra edilir. Yörede bu oyuna Mengi ya da Mengi Zeybeği deme adeti de vardır.

Günday'ın Mengi'ye dair ifadesi ise şöyledir: Düğünlerde, bayramlarda, özel günlerde çalınıp söylenen eğlence amaçlı müziktir. Silifke ve Mut'ta bu oyuna Mengi denir. Bulundukları bölgenin samahları ile benzerlik gösterirler. Samahlar bölümlü iken mengiler tek bölümlüdür. Eğlence amacı taşıdığından 
samah icrasında kullanılmayan müzik aletleri de mengi icrasında kullanılmaktadır. Örneğin Gırbız Kemanesi, Klarinet ve Dırnak Kemanesi gibi... (Günday, 1997, s. 73-74).

Mengi kadınlı erkekli düz formda ya da dairevi oynanır. Karşılıklı iki sıra ya da halka halinde olmak üzere iki türlüdür. Mengiler davul, köşeli davul, kabak kemane, zilli def, kaval ve cura eşliğinde oynanır. Mengi oyununda diz kırmalar, sekmeler, öne doğru eğilmeler ve kol sallamalar genel figürdür. Samahları okşar yanı vardır. Güzelleme, dostluk vb. temalı olup samahın dindışı ortamda-dışarı samahı olarak-oynanmasına mengi denir.

Akdeniz ve Ege Tahtacıları arasında gözlemlediğimiz Mengi oyununu genç kız ve erkekler cemal cemale/yüz yüze dizilerek ve de parmaklara ağaç kaşık sıkıştırıp şaklatarak icra ederler. Sazların ritmine uygun tempoda ayak parmaklarında yaylanarak dizlerin gövdeye amud halde yükselip sekmelerini sağlar. Parmaklar boş olduğu zaman diz yukarı kalkıp sektiği esnada iki el diz bükümü dibinde birbirine vurulur. Bu tarz mengi oyununun Antalya, Burdur Teke Zortlatması, Sallama ve Konya Kaşık Oyunu ile pek çok benzerliği vardır.

Mengilerde özellikle vücudun bütün uzuvları estetik yönden ifadeye katılırlar. Ayaklarda sekmeler, diz kırmalar, belin eğilip bükülmesi, kolların çalımlı ve edalı sallanması, yüzün sevecen, hoş, insani görünüşü/ifadesi ile bu güzelliğe katılması bir ahenk teşkil eder (Seyhan, 1967, s. 4580). Halka şeklindeki mengilerde bir kadın ve bir erkek ikili sıralanır. Kadın ve erkek birbirlerinin yüzüne bakarak, samahta olduğu gibi cemal cemale oynarlar. Her oyuncu bir ölçü ezgi içinde iki değişik kişi ile karşs karşıya gelir. Güleç, sevgi ve şevkat duyguları ile yüz yüze gelerek...

Dügün ortamlarında saygın kişilerin şerefine, sevgi ve saygı belirtisi olarak da mengi oynanır. Menginin başını çeken oyuncu oyunu durdurur. Oyuncular yere çöker. Sazlar o anda susar. Bayraktar adlı kişi ortaya çıkar:

-Ne istiyorsunuz?

-Sevelim

-Kimi sevelim?

-Kayınbabayı sevelim.

Kayınbaba bulunup ortaya ortaya getirtilir. Sazlar mengi müziği ve ritmini icra eder. Kayınbaba oyuncularca havaya kaldırılır ve indirilir. Ardı sıra Keklik olsam, Pınar başı ve Antalya mengileri icra edilir. İcra edilen mengiler genellikle 9/8'lik usuldedir. Mengileri en az iki kişi oynar. Düğüne katılanların hepsi tarafindan birarada da mengi oynanır. Celal Necati Üçyıldız menginin dindışı 


\section{Daimi CENGİZ}

oyun olarak Tahtacıların simgesi olduğunu ifade eder. Bu oyunun Uzun Mengi (Horasani Mengi) ve Kısa Mengi (Alma Deresi, Pınar Baş1 Ben Olayım) olmak üzere ikiye ayrıldığını belirtir. Bu oyunda ayakların sürekli üçgen içinde gezindiğini, ikinci grubun da başka bir yanda olduğunu, ezgiye göre bazen çiftleme yapıldığını söyler. Mengi oyunları sırasında "sevme-isteme" diye bir bölümün de bulunduğunu yazmaktadır (Üçyıldız, 1979, s. 10-18).

Mengi oyununda öykünme de vardır. Örneğin Keklik mengisinde keklik kuşuna öykünme vardır. Keklik folklorda güzelliğin, sevgilinin sembolüdür. Kekliğin sekişi, kanat vuruşu, seslenişi, gerdan hareketi ve sıçrayışı hareketlerle taklit edilir. O insan olur meşe altından açığa çıkar. Kaşıklar kanat oluverir. Ayaklar seker. Bu mengi bir av-tabiat tasvirli danstır. Avcı-keklik düellosunun figürlü tasviridir.

2003 yılında Aydın Karacasu İlçesi Boyasın'da Tahtacılar ve Mengi oyunu üzerine alan çalışması yaptık. Kadın ve erkek kaynak kişilerle bu oyuna dair röportajlar yaptık. Mengi oyununu gözlemledik. Kaynak kişiler Eyüp Ceylan, Hasan Keskin, Elif Ceylan, İsmail Çetin ve Elif Tufan'dan ses ve görüntü kayıtları aldık. Kaynak kişilerin mengiye dair en çarpıcı deyişi:"Mengi Tahtacının mührüdür"ifadesi oldu. Uzun saplı bağlama eşliğinde üç etekli iki kadın mengiyi oynadı. Erkekler ise normal kıyafetleri ile oyuna katıldılar. Boyasınlılar şair Sefil Hüseyin'e ait bir nefes mengiyi icra ettiler:

Güzel Şah'tan bize bir dolu geldi

Bir sen iç sevdiğim bir de bana ver

Hünkar Hacı Bektaş-1 Veli'den geldi

Bir sen iç sevdiğim bir de bana ver

Yayım gelir erenlerin yayından

Muhammed neslinden Ali soyundan

Kirkların ezdiği engür suyundan

Bir sen iç sevdiğim bir de bana ver

Beline kuşanmış nurdan bir kemer

İçmişim doluyu yüreğim yanar

Herkes sevdiğinden bir dolu umar

Bir sen iç sevdiğim bir de bana ver

Herkes sevdiğini tanır sesinden

Şahım Muhammed'in Ali soyundan

Selman'ın köşkünü doldur bu sudan

Bir sen iç sevdiğim bir de bana ver 
Senin aşıkların kaynadı coştu

Kaynayıp coşanlar serinden geçti

Sefil Hüseyin'im bir dolu içti

Bir sen iç sevdiğim bir de bana ver (Cengiz, 2020, s.52-53).

Yanyatır Tahtacı obaları ise aynı mengi nefesi Pir Sultan Abdal mahlası ile okurlar. Burda şiir/nefes aynı sadece şiirin sonunda mahlas değişmektedir (Yetişen, 1986, s. 121). Bu şiir nefes İsparta ili Uluğbey ilçesi Alevi Ayın-I Cemi'nde samah olarak icra edilir. Ve Mengi-Samah olarak da bilinir (Cengiz, 2006, s. 126). Bu mengi oynanırken sazın kısa faslının ardından ve deyişin ilk sözleri ile birlikte sol ayağın üzerinde olan baş parmak sol ayaktan ayrılır ve mengi başlar. Mengideki bu ayak hareketi ayakların mührünün bozulması olup samaha özgü figürdür.

Bu mengi nefesinin ilk iki dörtlüğünde adeta ağırlama gibi görünen kısım "Beline kuşanmış nurdan bir kemer" dizesine geldiğinde oyuncular daha coşkulu ve yürük oynamaya başlarlar. Coşku artar ve "şaplak" ile dışa vurulur. İzleyiciler de mengi oynayanlara "şaplak" ile eşlik ederler.

Nefesin son dörtlüğünün icrasında kadınların üç etekleri açılıp kanatlanır. Coşku ve hareket dorukta olur. Mengi samahın aksine coşku ile biter. Ama bu nefes samah olarak dönüldüğünde aynı nefesin son dörtlüğünün bitiminde samah ağırlaşır, selamla biter. Mengi nefesinin bitiminde oyuncular niyazlaşarak ayrılırlar. Bu pervane hali ve niyazlaşma samah ile menginin ilişkisine delalettir.

Aşağıda aktaracağımı Mengiler olarak oynanan diğer nefesler ise varyantları ile birlikte Pir Sultan Abdal, Şah Hatayi ve Kul Himmet'e aittirler:

Ala gözlü Şah'tan bir dolu geldi

Bir sen iç sevdiğim bir de bana ver

Hünkâr Hacı Bektaşi Veli'den geldi Bir sen iç sevdiğim bir de bana ver

Herkes sevdiğini bilir sesinden

Dinleyin erenler arı esende

Kırkların ezdiği engur şiresinden

Bir sen iç efendim bir de bana ver

Kuşağın beline yapoladdan kemer İçmişim doluyu ciğerim yanar Herkes sevdiğinden bir dolu umar Bir sen iç sevdiğim bir de bana ver. 


\section{Daimi CENGİZ}

*** $*$

Aşağıdaki nefes ise Şah Hatayi/Şah İsmail'e ait bir şathiyedir.

Bizden selam söyleyin Kul Himmet kardeşe

Vücudum şehrini gezsin de gelsin

Yedi gat yer ilen yedi gat gögün

Onun manasinı versin de gelsin

Benim aradığım Hazreti Ali

Altundan döğülmüş Düldül'ün nalı

Kırk arşın kuyudan kim çıkarmış bu yolu

$\mathrm{Bu}$ yolun tarikini sürsün de gelsin

Dervişlik dediğin bir kolay işdur

Ali'nin gördüğü mübarek düşdür

Canı yok cinsi yok bu nasıl düştür

$\mathrm{Bu}$ kuşun dilinden bilsin de gelsin

Derviş dediğin arıdur özü

Araya $\mathrm{m} 1$ getti garibin sözü

Gımışka demirinin üstünde karınca izi

Karanlık gecede görsün de gelsin

Der ki Şah Hatayım özümüz darda

Ben seni sakınırım aygar nazarda

Çıkmadık canda kazılmadık mezarda

Cenaze namazın kılsın da gelsin $* * *$

Engürü dağından bir yol azıttım Acep Şah'a giden yollar bu m'ola Sarard gül benzin döndü havaya Acep pire giden yollar bu m'ola

Nice pınarım var dolar eksilir Ardıç dallarına gök dekeler asılı Kımıcı boran tutmuş beller kesilir Acep pire giden yollar bu m'ola

Nice pınarım vardır üstü boğalı

Daşı kimyeli de toprağı dualı Sarp kayalarımız var şahin yuvalı Acep pire giden yollar bu m'ola 
Merdivenden dertli gönül merdivenden

Aladağ'ın ardından da Şah Abbas'ın yurdundan

Kanlı yaş akıttım da o yârin derdinden eyzan

Acep pire giden yollar bu m'ola

Pir Sultan Abdal'ım coşup giderim

$\mathrm{El}$ gün arasına düşüp giderim

Köpüklenmiş selim aşup giderim

Acep pire giden yollar bu m'ola

***

Şunca güzelleri seyran eyledim

Salınca meylini salsa ikisi

Birisi sağımda biri solumda

Muhabbet meylini salsa ikisi

Kurbanım avaza mailem sese

Ecel tekmil olur ömür bek kısa

Muhammet su dökse Şah Âlim yusa

Dikse kefenimi sarsa ikisi

Al yeşil geyinmiş göğdür donları

Mevlam ruhsat verse görsek onları

Şefaat dileriz mahşer günleri

Sin'de sualimi sorsa ikisi

Yaz bahar ayında baharım çağı

Eridi yüreğim kalmadı yă̆1

Dostum bahçesine kurmuş otağ1

Aleme bir düzen kursa ikisi

Kul Himmet'im bu divandan geçersin

Utanacak işi nice tutarsın

Günde yüzbin canı azat edersin

Uçmak kapısında dursa ikisi

Antalya yöresinde üç bölümlü samah olarak dönülen Yüce Dağ Başında Bir Koyun Meler ezgisi Tahtacılarda kısmen de olsa mengi formunda iki bölümlü yarı samahi olarak icra edilir:

Yüce dağ başında bir koyun meler

Goyunun sesleri de yar bağrımı deler

Ne melersin goyunum vaz geç kuzundan 


\section{Daimi CENGİZ}

Koyunu güdersin kuzu gütmezsin

Güttüceğin yerde otlar bitmesin

Kız bana geleydin ölürmün acından

Ögütler mi aldın anandan bacından

Kız ben ölüyom senin öcünden

Eskiden sevdiğim sen değil misin

Yeniden sevdiğim sen değil misin

Elmanın irisini yüke tutarlar

Çürük çarığını yabana atarlar

Kiz ilen gelini bir mi tutarlar

Yorma gelin yorma seyran senindir

Hünkârım beyim aman, sultanım canım aman

Dönüver usul boylum meydana gelin aman

Hünkârım beyim aman, sultanım canım aman

Dönüver usul boylum, meydana gelin yar gelin

Yörede ikili mengi az oynanır. Çoklu mengi halayların çekildiği yönde soldan sağa doğru dönülerek oynanır. Yöre halkı samahtan sonra mengiyi özel bir yere koyuyor. Çünkü "Mengi Tahtacıların mührüdür".

Tahtacılar mengi oyununun zahirler karşısında oynanmasında mahsur görmezler. Mengi oyunu esnasında dem alır, rakı içerler. Mengi repertuarının bir kesimi samah nefesleri ile aynı ya da yakın nefeslerden oluşur. Bu nefesler: Ala Gözlü Şah'tan Bir Dolu Geldi, Bizlere Bu Dolu Ali'den Geldi, Bizden Selam Söylen Kul Himmet Kardeşe, Engürü Dağından Bir Yol Azıttım. Mengü nefesleri genellikle ulu Alevi-Bektaşi şairlerine ait nefeslerdir.

Mengiler iki türe ayrılır: Eski Mengiler: Sen Bir Bezirgân Ol, Aşağıdan Gelen Beserek, Pınara Vurdum Kazmayı... Yeni Mengiler: Keklik Olsam, Pınar Başı Ben Olayım, Evlerinin Önü... Kaşık türü oyunlara örnek olarak Silifke yöresi Tahtacılarının kaşık eşliğinde oynadıkları oyunları örnek olarak verebiliriz: Yayla Yolları, Keklik, Silifke Sallaması, Türkmen K1z1... Bu oyunlar ellerde kaşık ve zil ile oynanan oyunlardır (Ünal ve Anlıtamar; 2004, s.15).

$\mathrm{Bu}$ örneklerden de anlaş1lıyor ki mengileri İtikadi ve İtikat Dışı tema işleyenler olarak ayırmak gerekiyor. İtikadi Mengi için yukarıda verdiğimiz Pir Sultan ya da Sefil Hüseyin'e ait nefes örnek teşkil eder. İtikat Dışı tema işleyen mengiye dair ise şu Horasani Mengi'yi örnek verebiliriz: 
Aşağıdan gelen urum koyunu

Selviye benzettim yârin boyunu

Kendi güzel amma bilmem huyunu

Ben bir servi boylu yardan ayrildim

Her daim kış gitmez bir de yaz gelir

Çok durma belki de söz gelir

Misır'ın hazinesini versem belki de az gelir

Urum haraç da yoluna kurban

Ak gerdan üstünde çifte gülün var

Kalem kaş üstünde sümbül telin var

Ne doyup usanacak tatl dilin var

Uğrun uğrun yüzüme gülmeyeydin

Tavus kuşu gibi göğsü nakışlı

Kaldırmış üsküpün doğan bakışlı

Güvercin topuklu keklik sekişli

Ver Allahım ver bir civan gönlüm eyleyem (Web 1).

Ö. Seyhan'ın" Aşağıda gelen türlü beserek" adlı mengisini Eski Mengi'ye, İtikat Dışı mengiye örnek olarak bir dörtlük metni ve notası ile birlikte verebiliriz:

Aşağıdan gelen türlü beserek

Çekip gelir ökçesine basarak

Kendi güzel amma boyu kısarak

Ben bir orta boylu dosttan ayrıldım (Seyhan,1967, s. 458) 

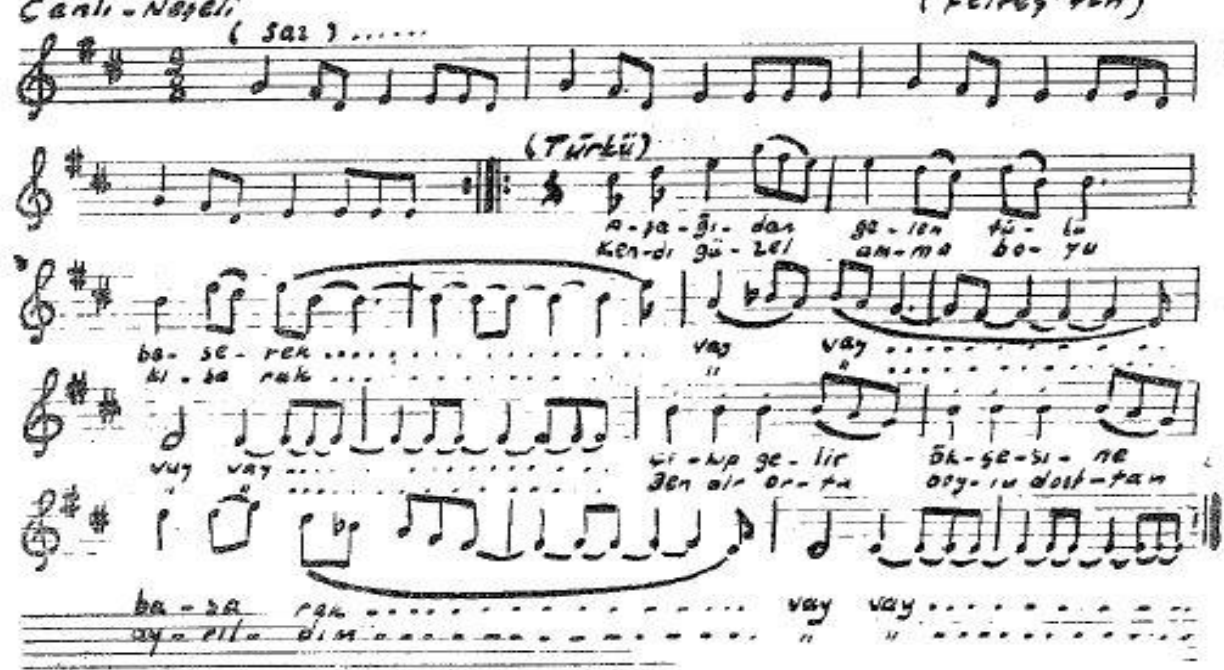

7oy, \&u mangi, daip sablinde oynamr

Yine bir dörtlük söz metni ve notası ile İtikat Dışı Yeni Mengi'ye örnek olarak Keklik Olsam mengisini örnek verebiliriz:

Keklik olsam yuva yapsam

Ben de bağlara bağlara

Ben yârimi alsam kaçsam

Yüce dağlara dağlara (Seyhan, 1967, s. 4582). 


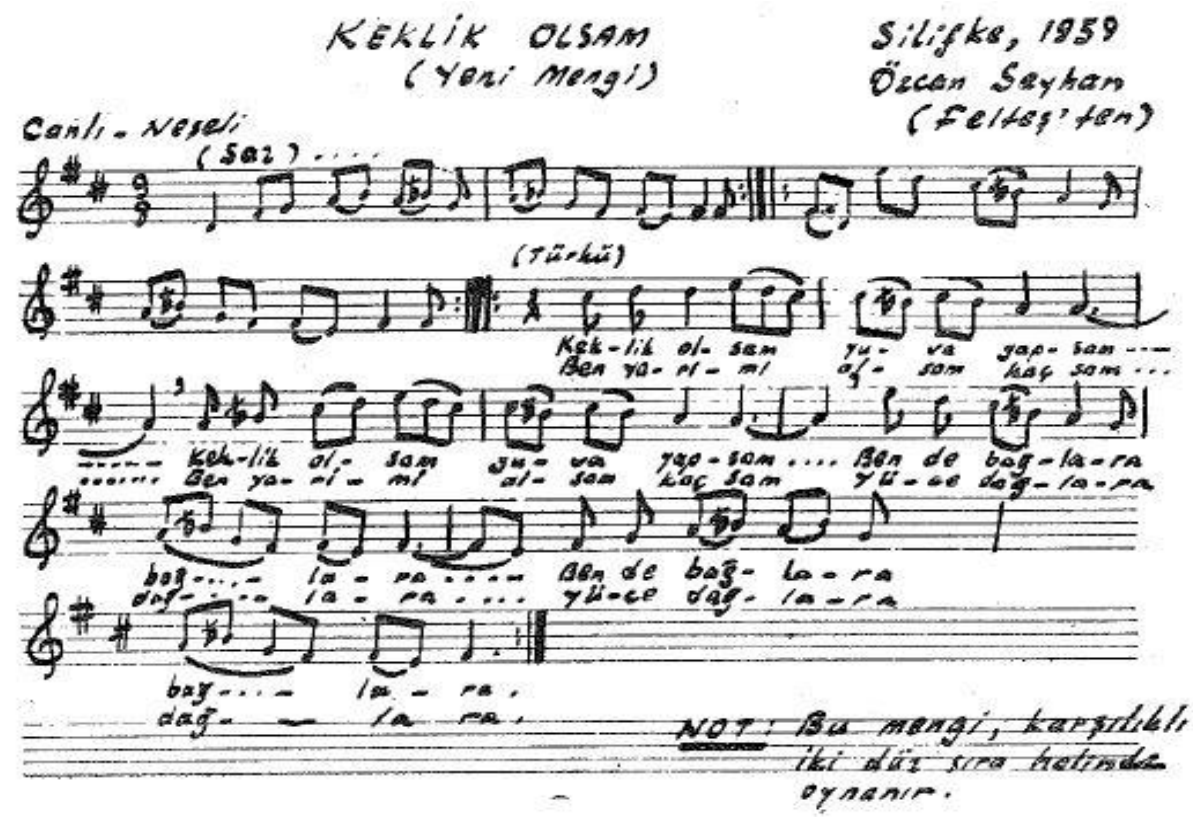

Mengi oyununa eşlik eden sazlar genellikle şunlardır: Bağlama, Kemane, Kaval, Kabak Kemane, Zilli Def, Köşeli Davul ve Cura. Mengi icrasındaki eşlik için bağlama aşık düzenine göre akort edilir. Kemaneye eski Tırnak Kemanesi akordu çekilir. Dizde çalınır. Zilli Def iki elle havada çalınır. Köşeli Davul ise kucakta çalınır. 


\section{Daimi CENGIZZ}

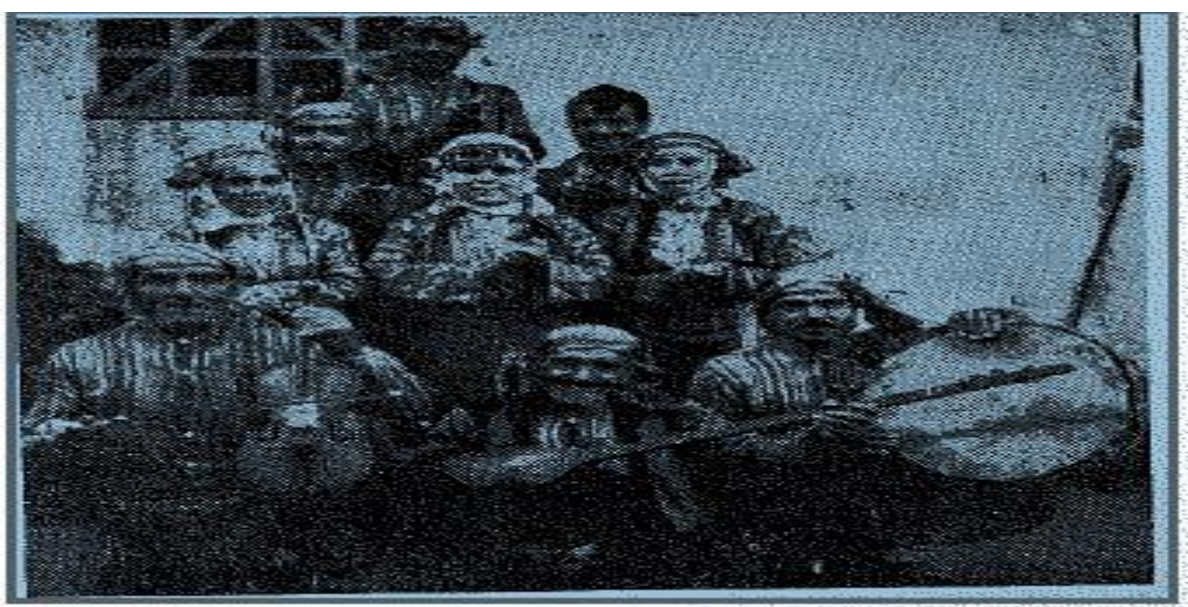

Tahtacılar eskide 'Dırnak Kemanesi' adı verilen keman çalarlarmış. Kıbrıstan getirilen Batı Kemanına yörede Gırbız Kemane denir. Daha sonra Dırnak Kemanesinin yerini Gırbız Kemanesi denilen Batı kemanı alır. Bu kemaneyi Silifke ile Antalya arasındaki Tahtacilar mengi icrasında kullanırlar. Kıbrıs 16. yy'da fethedildiğinde Silifke, Antalya, Karaman ve Torosların bir çok zirvesinden Tahtacı Türkmen obaları göçertilir. Menginin bu göçler sonucu Kıbrıs'a da gittiği muhtemeldir.

Mengi 9 vuruşlu bir oyundur. Horasan'dan geldikleri için icra ettikleri bazı mengilere Eski Horasani Mengi denmektedir. Bu mengilerin mistik olan 9 zamanlılarına samah, profan/dindışı olanlarına da Mengi adı verilir. Samahları gizli tutarlar. Ama mengileri açıkça oynamakta sakınca görmezler. Mengileri kendi toplumları dışında oynarlarsa ceketlerini ters giyerler. $\mathrm{Bu}$ uğur ve uğursuzluk telakkisi ile alakalıdır.

Mengi oyununda el ele tutunma yoktur. El çırpma vardır. 9/8'lik usul dahilinde oyuna 2223 kalıpta Hey! Hey! naraları ile gidilir ve gelinir. Usulün ilk ikilisinde ve son üçlüde Hey! denilir. Tahta biçerken de bu ritmi icra ederler. Tahta kesiminde "çekme-yitme" ritmi olan 222 3'lük kalıp "çek-yit, çek-yit" sesleri ile ifade edilir. Çalışma hayatı, iş hayatının ritmini mengi oyununun musikisinde kalıp olarak bariz şekilde görmek mümkündür. 


\section{SONUÇ}

Tahtacılar Horasan'dan gelip zaman içinde Toroslar boyunca Akdenizden Ege'ye ulaşıp mekân tutan Alevi Türkmen boylarıdır. 16 yy'da Y. Sultan Selim'in Alevi/Kızılbaş siyaseti (1514) sonrası Akdeniz ve Ege'de dağların kuytuluk kesimlerine çekilip ağaçişi, tahtacıllı̆ı kendilerine meslek edinen Ağaçeri topluluklarıdır. Bu meslek zamanla ad olarak onların Türkmenliğini ve Aleviliğini ikinci plana itti. İçeride Türkmen Alevisi ve dışarıdan Tahtacılar olarak bilindiler. Tahtacıların geleneksel yaşamı ağaca bağlı, ekolojik koruma ve denge üzerine kuruludur. Doğa dostu bir topluluktur.

Akdeniz ve Ege'nin bu kadim topluluğu Şamanist doğa inancı ve batıni tasavvufi Heterodoks itikat öğelerini bir arada yaşar. Yakın zamana kadar geleneklerinde var olan İslam öncesi Türk yaşam tarzı orijinini bozmadan saklı tutar.

Biz "Mengi Tahtacının mührüdür" ifadesinden hareketle Tahtacıların mengi oyununa dair bilinmeyeni, dağınık halde olan bilgi kırıntılarını literatür taraması yaparak ve alanda kayıt alarak mengi oyununa dair bir dağarcık oluşturduk. Mengilerin oyun olarak ocak bağlantılarını ve Akdeniz üzerinden Ege'ye yayılan güzergahını belirledik.

Dügün, nişan, sünnet vb. eğlence ortamlarında icra edilen, Dışarı Samahı ve Tarikat Samahı denilen menginin Alevi-Bektaşi Ayin-i Cemi'nde icra edilen samah ile tema, figür ve hareket olarak örtüşen ve ayrılan yanını tespit ettik. Yani Ayın-i Cem'de dönülen samahlarla olan farklılığını ortaya koyduk. Alanda derlediğimiz mengi repertuarından hareketle mengileri Eski Mengiler ve Yeni Mengiler adı altında ve İtikadi Mengiler/Mistik Mengiler ve İtikat Dışı Mengiler olarak tasnif ettik. Böylece tür ve hareket tarzı itibarıyla Mengiler bir sistematiğe/tasnife kavuşmuş oldu.

Mengi samahi özellikler taşıyan, samah ile karşılama arası bir eğlence amaçlı oyundur. Diğer bir ifade ile samahın dindışı ortamda-dışarı samahı olarakoynanmasına mengi denir. Mengi eğlenceye katılan tüm katılımcılarla da oynanır. Samah belirli sayıdaki semazenlerle dönülür. Mengideki dairevi dönüşler ve ayak mühürlenmesi samaha dairdir. Samah ağırlaşıp selama gidilerek biter. Mengi coşkulu hareketlerle biter. Mengi zahir kişilerce izlenir ama samah zahir kişilerce izlenmez. Samah nefesleri menginin söz unsuru olabilir. Ancak menginin her söz unsuru samaha nefes olamaz. Mengiler 9 vuruşlu aksak usullüdür. Samahlarda usul, vuruş çeşitlidir. 


\section{Daimi CENGIZZ}

Tahtacılık, ağaç işçiliğgi mesleğinin iş ritmi ile menginin usul ve ritmi arasında bire-bir ilişkiyi tespit ettik. Bu ritim 22223 kalıbı olup 9/8'lik usul düzümüne denktir.

\section{KAYNAKÇA / REFERENCES}

Aksüt, A. (2003). Önce Türkmen Sonra Tahtacı. Kayhan Matbaası.

Atalay, B. ( 1991). Divanü Lügat-it Türk. TDK Yayınları.

Cengiz, D. (2006). Azerbaycan ve Türkiye'de Nevruz'un Mevcutluğu ve Melopoetik Hususiyetleri. Doktora tezi, Azerbaycan Müzik Akademisi Müzikoloji Bölümü.

Cengiz, D. (2006). Halkbilim Yazıları. Duvar Yayınları.

Çıblak, N. (2005). Mersin Tahtacıları Halkbilim Araştırmaları. Ürün Yayınları.

Gazimihal, M. R. (1951). Bengi Oyunu, TFA Dergisi, 1(22).

Günday, A. (1997). Dünden Bugüne Fethiye. Demşah Rehberlik.

Korkmaz, E. (1994). Ansiklopedik Alevi-Bektaşilik Terimleri Sözlügü. Ant Yayınları.

Kehl-Bodrogi, K. (1987). Die Tahtacı Vorlaufiger Bericht über eine EtnischReligiöze Traditioneller Hozarbeiter Anatolien.

Kum, N. (1950). Türkmen, Yörük ve Tahtacılar arasinda tetkikler, görüşler. TFA Dergisi, 1(11).

Küçük, M. (2009). Cemaat-ı Tahtaciyan. Horasan Yayınları.

Orhonlu, C. (1957). Osmanlı Imparatorluğunda Aşiretlerin İskânı. Eren Yayınları.

Seyhan, Ö. (1967). Silifke Yöresinde Tahtacılar ve Mengi. TFA Dergisi, 11(220).

Sümer, F. (1972). Oğuzlar (Türkmenler), Tarihleri, Boy Teşkilatı, Destanları. DTCF.

Sümer, F. (1980). Oğuzlar (Türkmenler). Ant Yayınları.

Turkay; C. (1979). Başbakanlık Arşivi Belgelerine göre Osmanlı Imparatorluğunda Oymak, Aşiret ve Cemaatler.

Üçyıldız, C. N. (1979). Silifke ve yöresinde Tahtacı Türkmenlerde Gelenekler. Folklora Doğru, 5(50). 
Ünal, Ş. \& Anlıtamer, F. (2004). Seçilmiş Halk Oyunları, Teori ve Pratiği. Beyaz Yayınları.

Yetişen, R. (1986). Tahtacı Aşireti (Adet, Gelenek ve Görenekler). Memleket Gazetecilik ve Matbaacıllk.

\section{INTERNET KAYNAKLARI}

Web1: mengi-samah-kırt1//https://kirtil33.Tripool.com, Erişim tarihi: 21.07.2021

\section{FOTOĞRAFLAR}

Türkiye Folklor Araştırması Dergisi (1967), Cilt 11, Sayı Kasım 1967/220, s.4581-4585

\section{SÖZLÜ KAYNAKLAR}

Aysel Yıldız (2004), Mersin ili Silifke İlçesi Kırtıl Köyü, 1949 doğumlu Esma Miçer (2003), Muğla ili Milas İlçesi Koru Köyü, 1930 doğumlu Eyüp Ceylan (2003), Aydın ili Karacasu ilçesi Boyasın Köyü, 1954 doğumlu Hasan Keskin (2003), Aydın ili Karacasu ilçesi Boyasın Köyü, 1929 doğumlu Elif Ceylan (2003), Aydın ili Karacasu ilçesi Boyası Köyü, 1959 doğumlu İsmail Çakar (2004), Antalya ili Elmalı ilçesi Akçainiş köyü, 1922 doğumlu İsmail Çetin (2003), Aydın ili Karacasu ilçesi Boyasın Köyü, 1932 doğumlu Elif Tufan (2003), Aydın ili Karacasu ilçesi Boyasın Köyü, 1932 doğumlu 


\section{EXTENDED ABSTRACT}

Our research is about the Mengi game of Tahtac1 Turkmen Alevis. In order to understand the Mengi game, it is necessary to learn about the origin, history, geographical habitats, beliefs and lifestyles of the Tahtacı Turkmen tribes. We used field study data and written sources to get to know and make sense of Tahtaci Turkmen Alevis and their Mengi game. In the light of these data, we concluded our review. In this study, we adopted the qualitative research method as a guide.

The word Tahtac has no racial meaning. This name is given to the Turkish tribe, which is engaged in the practice of mowing and slicing wood in the forest, instead of animal husbandry and agriculture. These tribes are the sons of Agaceri Turkmens and they carry the Alevism creed. Turkmen Tahtacis are the Alevi Turkmen community who came from Khorasan and settled in Anatolia. Shamanist and esoteric Hetcrodoks live together in their beliefs.

As the Tahtacis were on their way from the Taurus Mountains along the Mediterranean coastline to the Aegean, they left behind two great hearths. They left İbrahim-i Sani, who was considered the pir of the Hac1 Emir Hearth, in Güvercinlik, Adana, and Dur Hasan Dede, the head of the Yanyatır Hearth, in a place called Dur Hasan in Ceyhan. The Tahtac1 tribes, which are inhabited in various parts of Anatolia, definitely belong to one of these two quarries.

After the Battle of Çaldıran (1514) by Yavuz Sultan Sclim, as a result of the continuous operation against the Alevi/Kızılbaş crews, some of the Turkmen Alevis took refuge in the mountainous nooks of the Mediterranean and Aegean regions. In these areas, woodworking and woodworking became their profession. For this reason, they were called Tahtaci from the outside professionally. But they defined themselves as Turkmen Alevis. The Tahtacis believe that the tree has its soul. They see the tree as a sacred value. For them, the tree is the shelter of the soul. Tahtaci is identical with the tree. The old tree is identical with the great and old people.

Tahtaci are descended from Agaceri. They are the descendants ofAgaceri. The consecration of the tree has a history of thousands of years in Anatolia. It is possible to see this clearly in Anatolian mythology.

The literature and field research data on the Tahtaci and their Mengi game are limited. Our aim is to compile the scattered literature and combine it with the field research data we have done, to push the limits of the known vocabulary about the Mengi game.

Mengi is traditionally played among the Tahtaci tribes. Tahtaci are descended from Agaceri. They are the descendants ofAgaceri. The consecration of the tree 
has a history of thousands of years in Anatolia. It is possible to see this clearly in Anatolian mythology. The literature and field research data on the Tahtaci and their Mengi game are limited. Our aim is to compile the scattered literature and combine it with the field research data we have done, to push the limits of the known vocabulary about the Mengi game.

Mengi is a folk dance traditionally played among the Tahtaci tribes and standing close to the sama. Mengi is a game between samah and welcome, which breaks off from samah but shows samahi game features. Mengi is about the outward life. Wedding, engagement, circumcision etc. performed by young people in entertainment. It is not played in the council of elders, it is a shame. Apart from Samah, Mengi is in the form of a folk song and is very active. It is played by young girls and boys by cracking wooden spoons.

In Teke region, Mengi is also the local name of the Zeibek dance performed together/group, yürük and mutual. It is performed in a circular order. There is also a custom in the region to call it Mengi or Mengi Zeibek. But Mengi stays closer to the sama rather than zeibek. For Mengi, it is possible to say: Mengi mainly stays close to the Sama, but it is a game form that is also under the influence of Zeibek from time to time.

There is the Mengi game played under the name of Out Samahi or Tarikat Samahi with the aim of informing and educating young boys and girls about the samah culture and game, performed in an entertainment environment of birth, wedding, circumcision and engagement. Mengi are of two types: 1. Ancient Mengis 2. New Mengis.

We particularly found the repertoire of Faithful Mengis and Non-Belief Mengis in the field. We determined the similarities and differences of the Believe Mengi with Samah in terms of theme, figure and movement style, and we recorded them through fieldwork. We determined that the Occupation/work rhythm (woodcutting rhythm) of woodcutters and the melodic rhythm and flat hearts of mengi (2 2223 ) are the same.

In the words of the Tahtacis, it is the "seal of Mengi Tahtac1". Tahtac1 is a traditional game played among Alevi Turkmens, and it is an enthusiastic game of greeting, which has characteristics close to Sama. In other words, Mengi is a game between samah and welcome, breaking off from samah and showing samahi features. 